\title{
CRYPTOCOCCAL MENINGITIS IN A DIAGNOSED AIDS PATIENT- A CASE REPORT
}

Shailendra B. Yadav¹, Kunal Goel2, Jaishree Tijare³, Dinkar Khumbalkar

${ }^{1}$ Assistant Professor, Department of Pathology, Government Medical College, Nagpur, Maharashtra.

${ }^{2} 2^{\text {nd }}$ Year Junior Resident, Department of Pathology, Government Medical College, Nagpur, Maharashtra.

${ }^{3}$ Associate Professor, Department of Pathology, Government Medical College, Nagpur, Maharashtra.

${ }^{4}$ Professor, Department of Pathology, Government Medical College, Nagpur, Maharashtra.

HOW TO CITE THIS ARTICLE: Yadav SB, Goel K, Tijare J, et al. Cryptococcal meningitis in a diagnosed aids patient- a case report. J. Evolution Med. Dent. Sci. 2018;7(04):546-547, D0I: 10.14260/jemds/2018/122

\section{PRESENTATION OF CASE}

A forty three year old man with HIV infection was admitted in the medical ward of Government Medical College and Hospital, Nagpur with complaints of headache, fever $\left(38.5^{\circ} \mathrm{C}\right)$ and neck rigidity for the last 4 days. CSF obtained by lumbar puncture was received in the Department of Pathology during night duty as resident pathology duty for TLC and DLC. Wet mount, Gram staining methylene blue and India ink preparation revealed $4-7 \mu \mathrm{m}$, round budding yeasts with capsule and 8 - 10 lymphocytes per high power field. CSF was cultured by standard procedures. Creamy white colonies were seen on Sabouraud dextrose agar medium. The identification and pathogenicity of Cryptococcus neoformans was established by growth at $37^{\circ} \mathrm{C}$, urease production test. Antigen detection was also done and titre, both in CSF and serum was 1615.

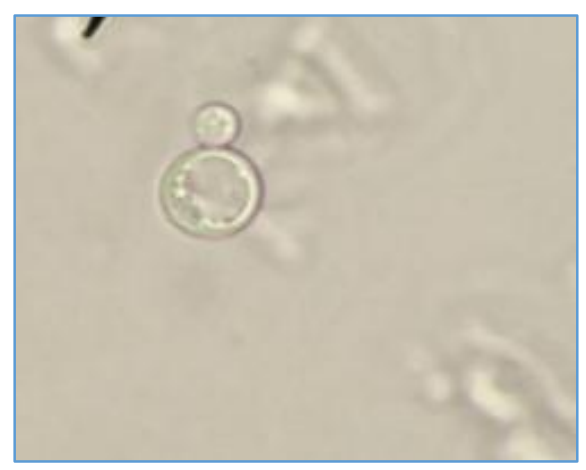

Figure 1. Wet Mount- Cryptococcus

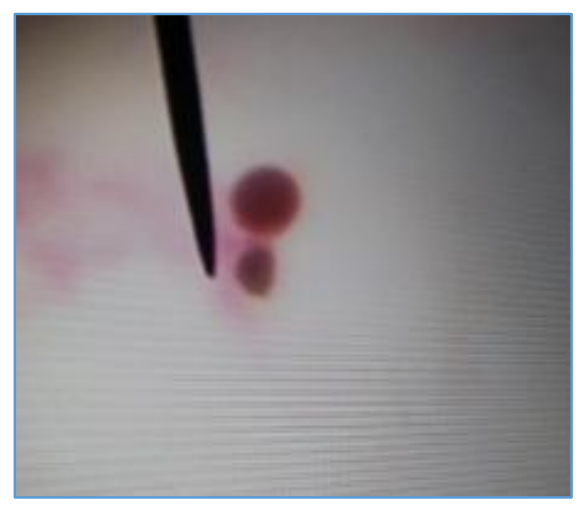

Figure 2. Gram Stain- Cryptococcus

'Financial or Other Competing Interest': None.

Submission 11-12-2017, Peer Review 07-01-2018,

Acceptance 13-01-2018, Published 22-01-2018.

Corresponding Author:

Dr. Shailendra B. Yadav,

\#307, Laxmi Plaza, Opp. Alexis Hospital,

Mankapur, Nagpur-30, Maharashtra.

E-mail: shylen268@gmail.com

DOI: $10.14260 /$ jemds $/ 2018 / 122$

(c) (i) $\$$

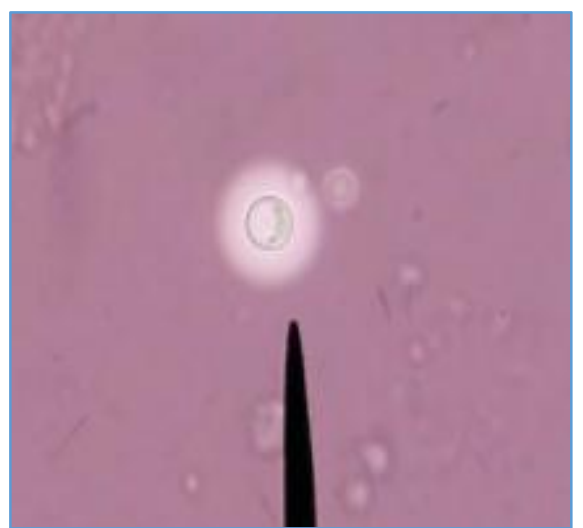

Figure 3. Methylene Blue (40x) Cryptococcus

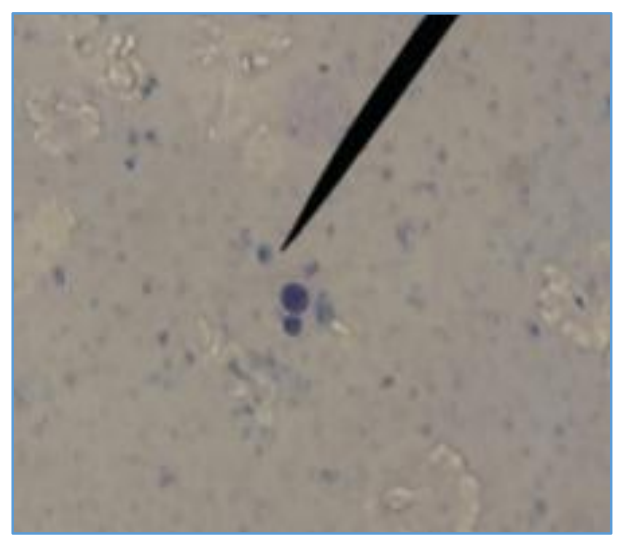

Figure 4. India Ink Preparation- Capsular

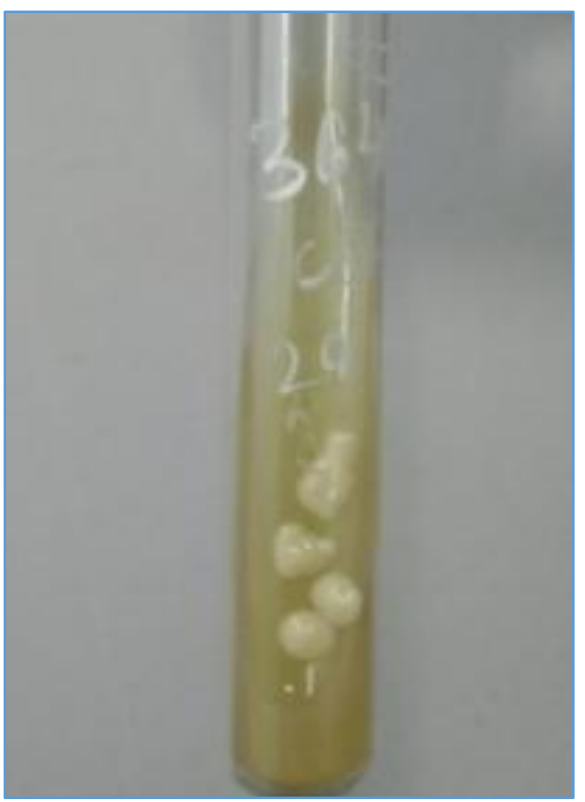

Figure 5. Sabouraud's Dextrose Agar showing Cryptococcus Colony 


\section{DIFFERENTIAL DIAGNOSES}

Pyogenic meningitis, viral meningitis, Guillain-Barre' syndrome, tubercular meningitis and Mollaret's meningitis. All these differential diagnoses are ruled out with confirmatory tests.

\section{PATHOLOGICAL DISCUSSION}

Cryptococcus neoformans is one of the most common opportunistic infection in AIDS. Cryptococcus neoformans exists in asexual or sexual forms. ${ }^{1}$ The asexual form is characterised by oval-to-spherical budding yeast cells with a polysaccharide capsule, while the sexual or perfect stage is characterised by the presence of basidiospores. ${ }^{1}$ The sexual form has not been described in association with clinical specimens and is observed only during mating. The asexual form with capsule is frequently seen in clinical specimens. ${ }^{2}$

Virulence is due to oxidase, protease enzymes and carbohydrate capsule, which can be demonstrated by negative staining with $10 \%$ Nigrosin or India Ink. Noncapsular mutant forms lack pathogenicity. Dioxide concentration favours capsule bioformation. Infections occur through inhalation of yeast cells in respiratory pathogens, then remain dormant depending on the host in immune system. Dissemination is due to serious defects in host immune system. The risk factors include advanced HIV stage, corticosteroid use, lymphomas, sarcoidosis, lymphoproliferative disorders, hypogammaglobulinaemia, systemic lupus erythematosus, cirrhosis and peritoneal dialysis. ${ }^{3,4}$

\section{DISCUSSION OF MANAGEMENT}

The patient responded to antifungal treatment (amphotericin $\mathrm{B}$ and fluconazole) but died later on due to renal failure.

\section{FINAL DIAGNOSIS}

Cryptococcal meningitis in immunocompromised host.

\section{REFERENCES}

[1] Mitchell TG, Perfect JR. Cryptococcosis in the era of AIDS--100 years after discovery of Cryptoccus neoformans. Clin Microbiol Rev 1995;8(4):515-48.

[2] Khanna N, Chandramuki A, Desai A, et al. Cryptococcal infection of Central Nervous System: an analysis of predisposing factors, laboratotory finding and outcome in patients from South India in special reference to HIV infection. J Med Mirobiol 1996;45(5):376-9.

[3] Harrison. A text book of internal medicine. 19th edn. USA: McGraw-Hill 2015:1340-2.

[4] Kauffman L, Blumer S. Cryptococcosis: the awakening giant. In: Pan American Health Organisation. Proceedings of the $4^{\text {th }}$ International Conference on Mycosis: the black and white yeasts. Washington, DC: Science Publication 1978:176-87. 